Military Technical College Kobry El-Kobbah, Cairo, Egypt

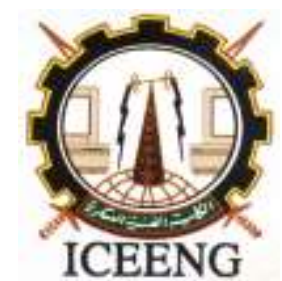

\section{$11^{\text {th }}$ International Conference on Electrical Engineering ICEENG 2018}

\title{
Detailed Analyses of the Failure and Repair Rates of Wind and Solar- PV Systems for RAM Assessment
}

\author{
M. El-Metwally ${ }^{*}$, M. EL-Shimy ${ }^{\star *}$, M. Elshahed ${ }^{*}$ and A. Sayed ${ }^{\star \star *}$
}

\begin{abstract}
This paper presents an extensive survey of the failure, and repair rates of wind, and solarPV energy conversion systems. Various practical layouts of these systems are presented considering various operation modes (i.e. off-grid, and grid-connected), and load types (i.e. deferrable, and non-deferrable). The presented layouts of wind and solar-PV energy systems cover various energy solutions for various operation modes, and load types. The overall structure of each system is separated into a set subsystems, then each subsystem is separated into a set of subassemblies or items. Considering repairable, and nonrepairable items, the analyses of failure, and repair rates are then performed for identifying the reliable performance, and weak items. The confidence of the results is increased by collecting huge amounts of data. These data cover various configurations, and meteorological conditions (i.e. stress factors) are analyzed and represented by their confidence median values. Salient conclusions are reached from the analyses of the collected data. The presented results are essential for performing a detailed Reliability, Availability, and Maintainability (RAM) of wind, and solar-PV systems. In addition, they are useful in identifying the weak items, for setting appropriate maintenance plans for increasing the overall reliability of the considered systems.
\end{abstract}

\section{KEY WORDS}

Failure rate; repair rate; reliability; photovoltaic (solar-PV) systems; wind energy systems; Reliability, Availability, and Maintainability (RAM).

\section{INTRODUCTION}

Recently, renewable resources specially wind and solar generations have been matured to a level of development where it is becoming ready to diffusion by larger amounts in bulk power generation [1]. In addition, highly sustainable large scale

* Dept. of Electrical Engineering, Cairo University, Giza, Egypt.

** Professor, Dept. of Electrical Power and Machines, Ain Shams, Cairo, Egypt. 
hydrogen-based energy system for combined fuel, and electricity production are expected to dominate in the future. The renewable energy and nuclear energy sources will provide the input energy required for the production of hydrogen, and hydrogen-based fuels [2]. This is not only due to the increasing energy demands, but also due to the increasing of carbon dioxide emissions (CDE) to the environment as a result of burning fossil fuels for power production, and the reduced reserves of fossil fuels.

Wind and solar renewable sources come in the second and the third place after the hydropower sources in the total worldwide installed capacity [3]. The installation of large scale wind and solar-PV systems around the world appears as a result of increasing of improvements in the wind turbine and PV system technologies. By the end of 2016, the world installed capacity of the onshore wind turbines and the solar-PV systems approximately reached $472 \mathrm{GW}$ and $303 \mathrm{MW}$ respectively, by an additional value of 52.4 GW for the wind and $75 \mathrm{GW}$ for the Solar-PV [3].

At the same time, there are several problems which face the renewable energy resources when compared with conventional energy sources [4 - 7]. The problems from an operational point of view arise from the fact that these resources are variable, and intermittent depending on the meteorological changes. These problems pose a major challenge in the electrical energy production, especially, in the case of used variable renewable energy as a main source for electrical power production [2]. These challenges are extended to the grid stability, security, power quality, and behavior during fault conditions in addition to the grid reliability [7 - 9].

The reliability of the renewable systems represents one of the major challenges to the development and economy of these systems $[10,11]$. There is an urgent need to assess, and enhance the reliability of these systems.

Reliability is the probability of a system or a subsystem or a subassembly to perform its function adequately, under the given operating conditions, for an intended period [10, 11]. This intended period is typically the lifetime of the system. Two relevant trends are tracked in the literature [10, 12 - 19]. The first trend focuses only on the reliability of the system vulnerable components, whereas the second trend studies the reliability of renewable energy production. The literature that discussed the first trend is much less in comparison with the literature of the second trend.

The reliability analysis of the system components depends on dividing the system into subsystems which composed of subassemblies or items. Elaboration of the reliability analysis is started from the subassemblies level to the subsystem level then the overall system. The main problem which faced literature that discusses this trend is the rarity of the related accurate reliability data of the subassemblies. This is not only due to the unavailability of such data in many wind farms and solar-PV plants, but also due to restrictions imposed on these data, and the high expenditure of retrieval of these data. Previously, the available limited data were collected from different plants and the reliability analysis has been completed without taking into consideration the impacts of various configurations of wind turbine generators (WTGs), and various layouts of the solar-PV and wind energy systems. In other cases, some simplifications were introduced in order to complete the reliability analysis when the reliability data of some subassemblies are unavailable [10-20]. Therefore, some literature discusses the reliability of the WTG system for the electrical subsystem only or the mechanical subsystem only. 
A summary of the previous literature findings is presented in the following. For WTGs [21-23], it found that:

> The interruption of the energy production of WTGs relates mainly to the failures of the electrical components where these failures represent the leading cause of lost days per annum.

$>$ The gearbox availability in the geared WTGs represents the critical item that affects the overall availability of WTGs. This is due to that the longest outage duration caused by gearbox failures, although its failure is rare.

> Generators in direct-drive WTGs (i.e. gearless WTGs) have a failure rate greater than and approximately twice the failure rate of indirect-drive generators. The generator used in direct drive WTGs has a number of stator and rotor coils larger than the generator that used in the indirect drive WTGs. Therefore, the disparity in failure rates is due to the larger number of coils used in the direct drive WTGs.

> The synchronous generator based WTGs have a failure rate greater than the failure rate of induction generator based WTGs operating in the fixed speed mode.

$>$ The WTGs with full-scale converters (FSCs), suffer from high failure rates due to the failures in the electronic switches.

For Solar-PV systems $[16-18,24]$ it is found that:

$>$ The inverter is the leading cause of failures in grid-connected solar-PV systems, while the second and third causes are respectively the failures of the string protection, and solar-PV modules.

$>$ The reliability of each subsystem decreases with time and with the number of subassemblies comprising the subsystem.

$>$ The decreasing rate of reliability in some subsystems is lower than other subsystems. This is due to the number of series and parallel subassemblies that represents the subsystem.

$>$ From the energy balance reliability point of view, the reliability of the gridconnected solar-PV systems with battery storage is greater than the reliability of the off-grid solar-PV systems with battery storage, which has reliability greater than off-grid solar-PV systems without battery storage.

$>$ From the system structural reliability point of view, there is a lack in the literature handling this issue. Therefore, this research focuses on this point.

The main objective of this paper is to introduce a detailed survey of the failure and repair rates of various subassemblies, subsystems, and systems for the energy production from solar-PV and wind energy systems. Various load types, and various operation modes take into consideration. This paper classifies the WTGs into three configurations; according to the operation modes, and operating concept. These configurations are fixed speed squirrel cage induction generator (FS-SCIG), the doubly fed induction generator which utilizes a partially rated converter (DFIG) and direct drive electrically excited synchronous generator with a fully rated converter (DDSG-FRC). The solar-PV systems in this paper are classified, according to the operation modes, into two configurations. These configurations the grid-connected and off-grid solar-PV systems. 
Deferrable and non-deferrable load types are introduced. In addition, the situations where the battery storage is required are carefully considered in the analysis.

\section{LAYOUTS OF SOLAR-PV AND WIND ENERGY SYSTEMS}

The selection between the appropriate layouts of the systems has a significant impact on the reliability. The selection of an appropriate layout depends on many factors such as the operation and control capabilities, and operating mode (i.e. off-grid, or gridconnected).

The grid-connected systems are ideally located close to the grid and its output is directly fed the grid. In fact, there are no needed for storage devices with grid-connected systems provided that the reliability of the grid is sufficient for supplying local loads. In this case, the power balance constraint for supplying the local load is secured by the grid, which acts as an energy storage with unlimited capacity. Based on the grid reliability level, the grid-connected systems are classified into two categories; grid-connected systems connected to either grid with insufficiently low reliability, or grid with sufficiently high reliability.

From consequent impacts of power interruptions, power system loads can be classified into three categories; non-essential, essential, and critical loads. The classification is mainly based on the techno-economic impacts of interrupting a specific load. Long power interruptions are acceptable in the case of non-essential load, while very short power interruptions are allowed in the case of essential loads. The critical loads should be interrupted even for very short durations. Consequently, in grid-connected solar-PV or wind systems where the grid reliability is insufficient, the energy storage is required for supplying essential and critical loads in the case of the grid outage [25-29]. The overall system, then acts as the Uninterruptable Power Supply (UPS).

On the other hand, off-grid renewable systems cover distinct situations where remote loads are difficult to reach electricity from the utility grid, or the traditional sources of electricity. The energy storage requirements in these systems depend on the load instantaneous power balance constraint. Two main load types are classified based on their instantaneous power balance requirements. The first type is the non-deferrable loads which required instantaneous power balance for their proper operation. Therefore, energy storage is required in off-grid systems that supply non-deferrable loads. On the other hand, the deferrable loads refer to a load type at which its energy requirements can be postponed to another nearby time. Water irrigation pumping systems present a popular example of deferrable loads [1]. Generally, off-grid systems supplying deferrable loads do not require electric energy storage; however, storage tanks may be used for utilizing the surplus power for water storage in irrigation water pumping systems. Fig. 1 illustrates the energy storage requirements for various operational modes, and load types. 


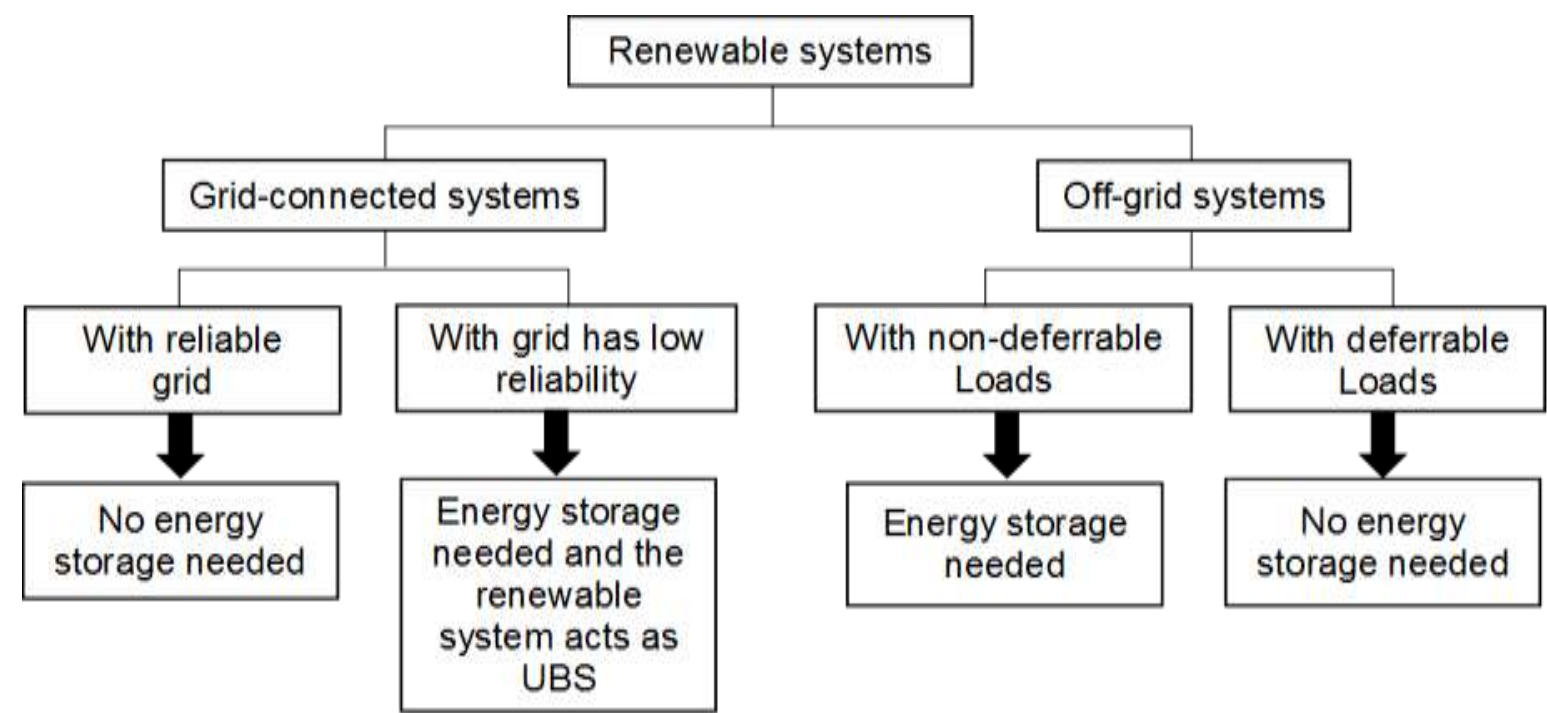

Fig.1. Energy storage requirements for various operational modes, and load types

\subsection{Solar PV systems}

Based on the previous discussion, and Fig. 1, Table 1 lists the various layouts of the solar-PV systems. In layouts without battery storage, the DC-DC converter acts as a charge controller, while it acts also as Maximum Power Point Tracker (MPPT) in layouts with battery storage. Grid-connected systems that are connected to a low reliability grid, the Automatic Static Transfer Switch (ASTS) is used for securing immediate proper islanding of the solar-PV system through its sensing, and switching control logics. In the island mode, the grid is disconnected due to either an outage, or a sever power quality problem. In this case, the non-essential load is isolated from the solar-PV system, while the energy required by the essential, and critical loads is produced from the solar-PV. The power balance is the island mode is secured by the battery energy storage. 
Table 1. Layouts of solar-PV systems

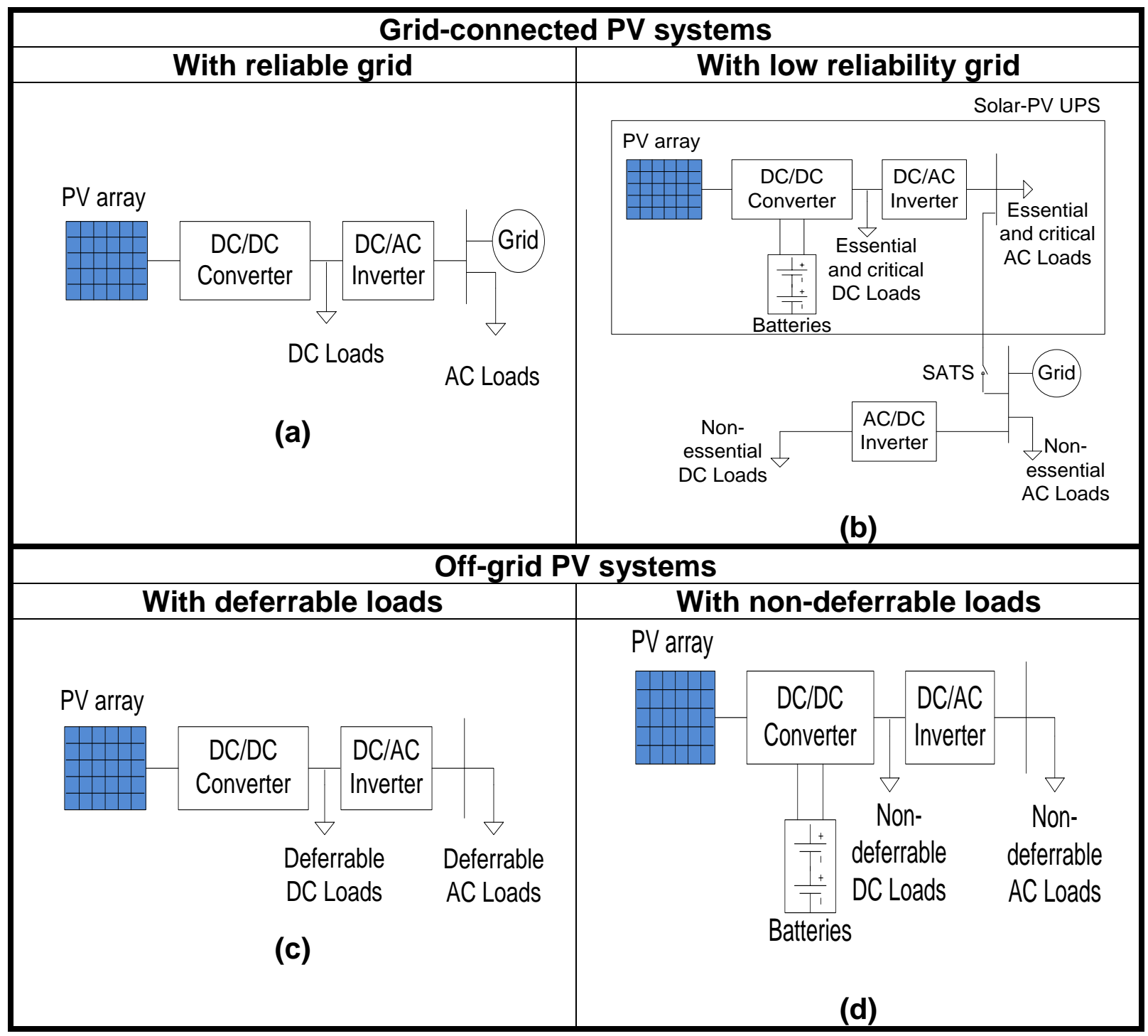

\subsection{Wind energy systems}

The same concepts of the layouts presented in this section are applied to solarPV as well as the wind energy system. Considering the previous discussions, and Fig. 1, Table 2 lists the various layouts of the wind energy systems. The shown WTGs will be considered in details in the next section where the FS-SCIG, DFIG, and DDSG-FRC are considered. 
Table 2. Layouts of wind energy systems

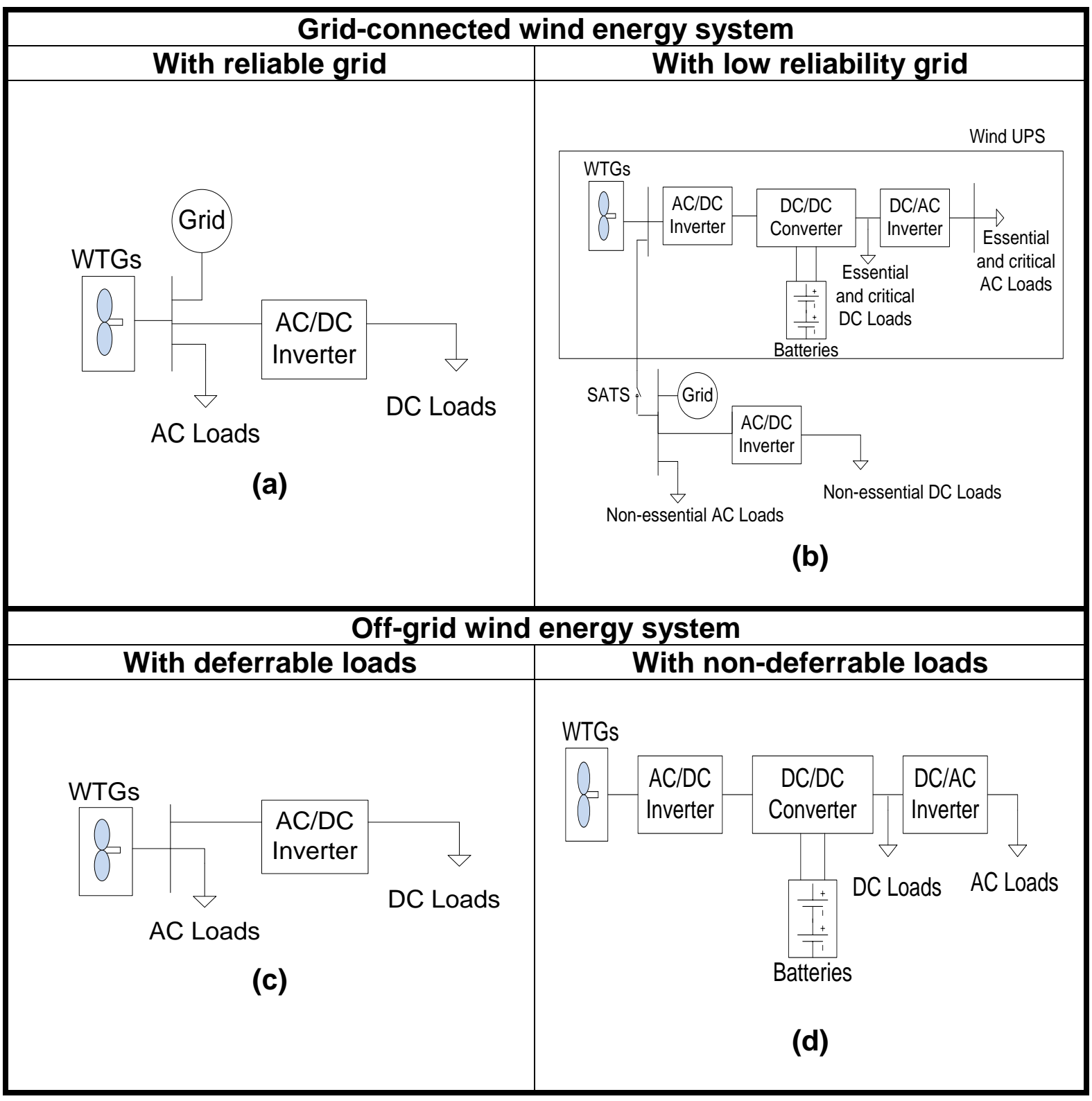

\section{FAILURE AND REPAIR RATES OF SOLAR-PV AND WIND ENERGY SYSTEMS}

There are two factors used for measuring the reliability, availability, and maintainability of any system. The first factor that demonstrates the reliability is either Mean Time Between Failure (MTBF) for repairable systems, or Mean Time To Fail (MTTF) for non-repairable systems. The major components comprising wind energy systems are considered repairable, while most of the components comprising solar-PV systems are non-repairable components. Therefore, the MTBF is used for demonstrating the reliability of wind energy systems, and the MTTF is used for demonstrating the reliability of solar-PV systems. The reciprocal of MTBF, or MTTF is the failure rate. 
Given that the maintainability is the measure of the ability of an item under given conditions of use, to be restored to a state in which it can perform its intended function(s) due maintenance actions. The maintainability is usually demonstrated by the repair rate, which is the reciprocal of the mean time to repair (MTTR). Therefore, the failure and repair rates are used in this paper to measure the reliability and maintainability of the subassemblies comprising solar-PV, and wind energy systems.

This part introduces through two stages. The first stage covers system decomposition whereas the second stage covers failure, and repair analyses.

\subsection{System decomposition}

In this stage, the main system will be decomposed into subsystems, according to their functions, which may be divided into subassemblies. Wind energy system is divided into three main subsystems; electrical, mechanical, other subsystems. On the other hand, the solar-PV system includes five subsystems; PV array, DC-DC converter, DC-AC inverter, balance of system (BOS), and battery storage subsystems. Each of these subsystems also contains subassemblies as shown in Fig. 2 and Fig. 3 for wind, and solarPV systems respectively.

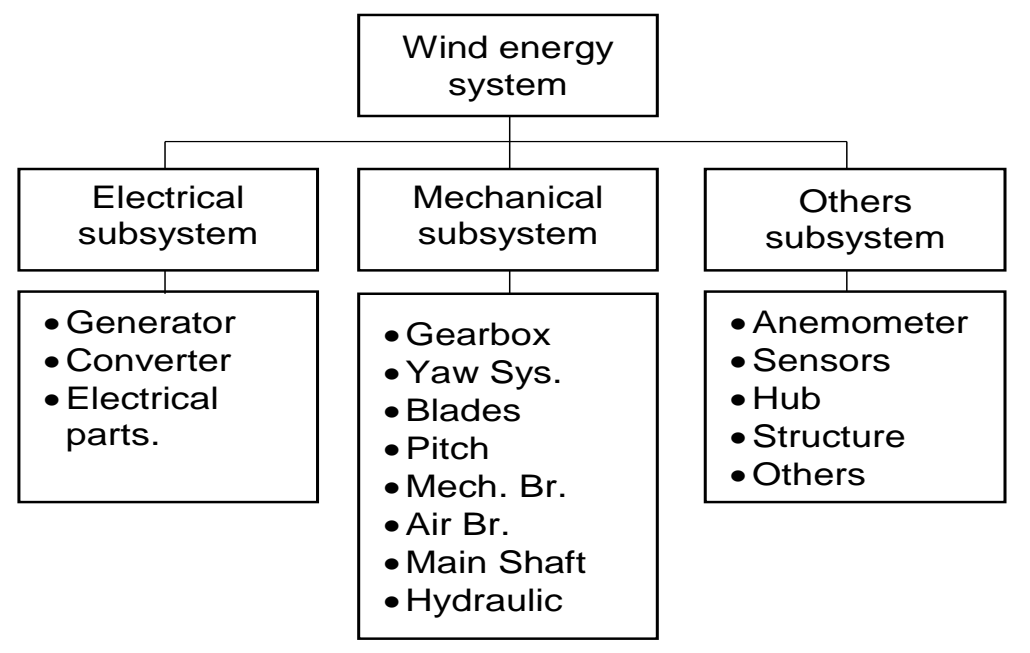

Fig. 2. Subsystems and subassemblies of a generic WTG. 


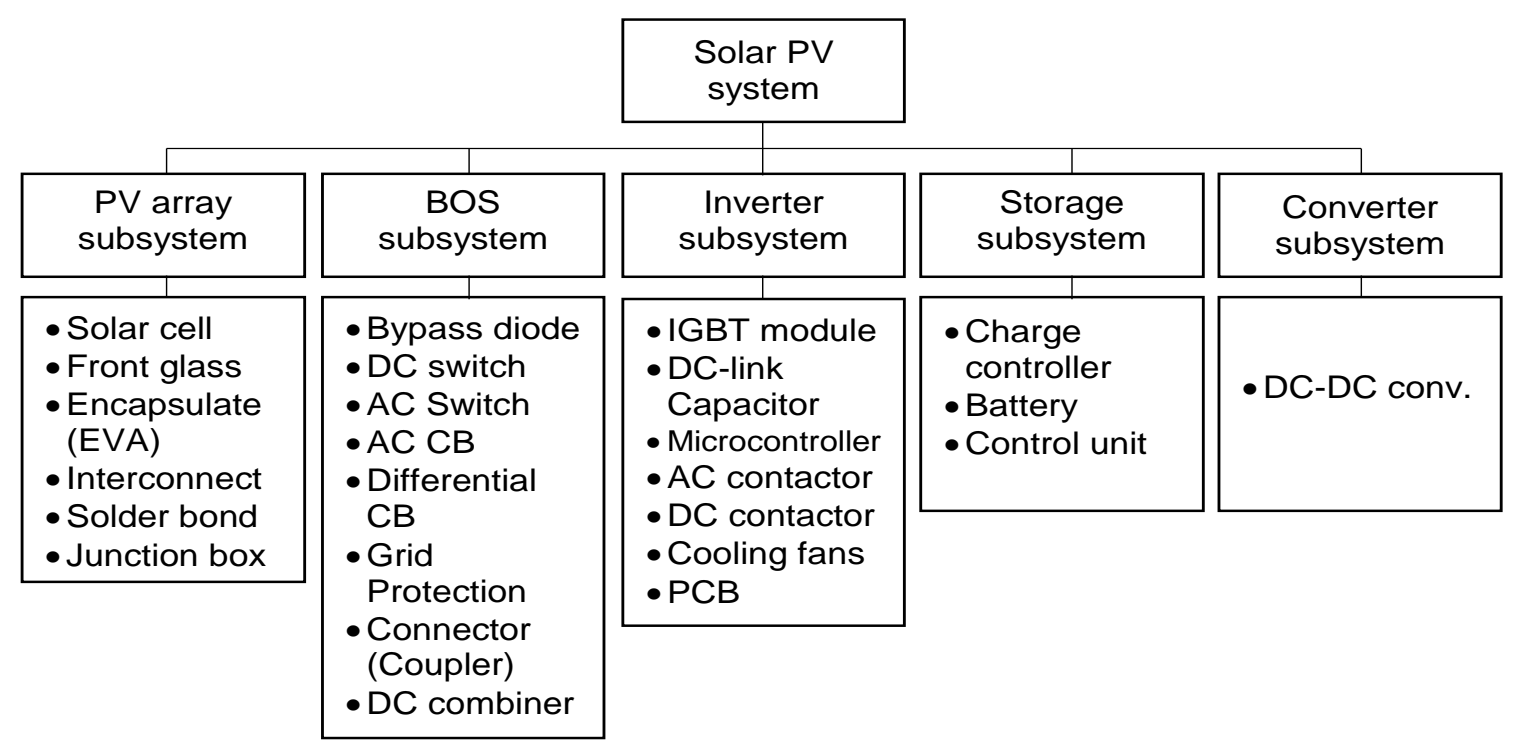

Fig. 3. Subsystems and subassemblies of a generic solar-PV system.

In order to obtain layouts simplification, some of these subassemblies are not notable on the layouts of the solar-PV system that listed in Table 1; however, these subassemblies have a significant impact on the reliability assessment, and they will be considered in the failure, and repair analyses. On the other hand, there are some subassemblies of the WTGs are absent from the considered configurations such as Converter, Air brake, and Gear box in FS-SCIG, DFIG-PRC, and DDSG-FRC configurations respectively.

\subsection{Failure and Repair Rates}

Collecting more realistic and accurate reliability data is very important for the whole RAM analysis. The Largest numbers of repair and failure data are collected from the literature. The obtained data cover various technologies, and layouts. In addition, the collected data are characterized by different scan times. These data are classified according to the various configurations and layouts of WTGs and solar-PV systems. The median value of the sorted data of each subassembly is then calculated. It noted that the use of the median values instead of the average values statistically decreases the uncertainties of the collected data per subassembly.

\subsubsection{Failure and Repair Rates of WTGs}

Fig. 4 shows the failure, and repair rates of the WTGs. The reliability data of the subassemblies of WTGs show in Fig. 4 are to show the difference between the various WTGs configurations used. It is depicted from Fig. 4 that:

D The failure rate of all electrical subassemblies in the DDSG-FSC configuration is higher than the others configurations (Fig. 4(a)). This is attributed to the larger number of windings on the stator, and rotor of the DDSC [22]. 
$>$ Among the electrical subassemblies, the electrical parts show the highest failure rates in FS-SCIG and DDSG-FRC whereas they show the lowest failure rate in the DFIG configuration (Fig. 4(a))

$>$ It is also clear from Fig. 4(b) that, the converter in the DDSG-FRC shows the highest repair rate among all the electrical subassemblies of the considered configurations. In addition, the electrical parts of the FS-SCIG and the DDSGFRC configurations show higher repair rates in comparison with the electrical subassemblies of each configuration. On the other hand, they show the lowest repair rate among the electrical subassemblies of the DFIG configuration.

$>$ Regarding the mechanical subassemblies shown in Fig 4(c) and Fig 4(d), blades, pitch control, and air brake show the highest failure rates among the mechanical subassemblies of the FS-SCIG, DDSG-FRC, and DFIG configurations. The electronics components (i.e. the converter) in the gearless DDSC-FRC configuration almost have a failure rate greater than the failure rate of the gearbox in the FS-SCIG, and DFIG configurations. It is also found that the failure rate of the gearbox in FS-SCIG is greater than that of DFIG-PRC. In the same subsystem, the repair rate of air brake, mechanical brake, and pitch control show the highest values in all configurations.

$>$ Regarding the last subsystem (i.e. others subsystem shown in Fig. 2), it is shown in Fig 4(e) and Fig 4(f), the hub and tower show significant failure rates or low reliability among the rest of the subassemblies in a given configuration, and among all configurations. In that subsystem, the other items also show high values of failure rates.

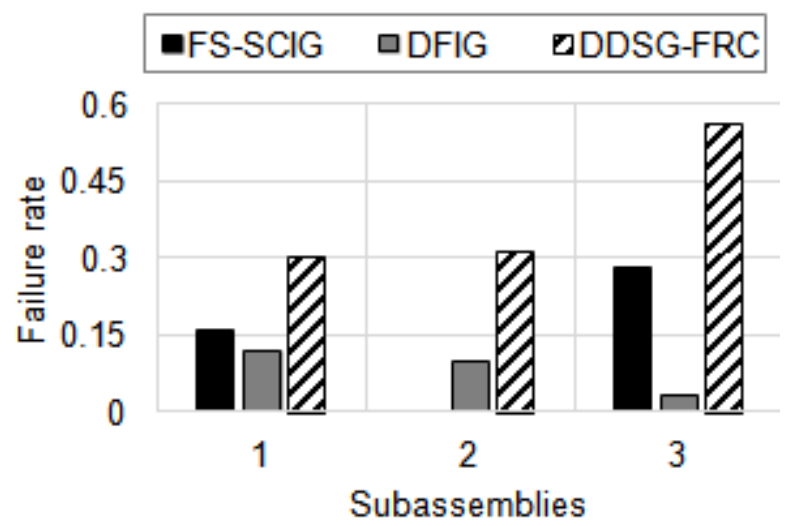

(a)

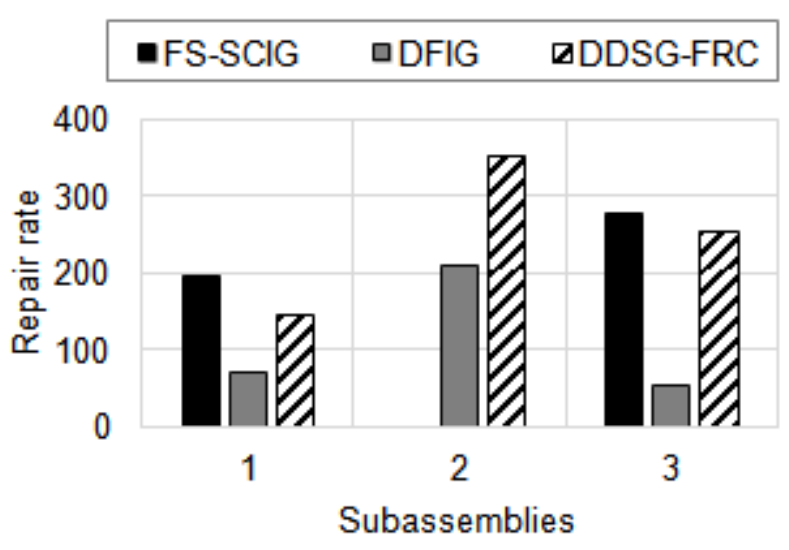

(b) 


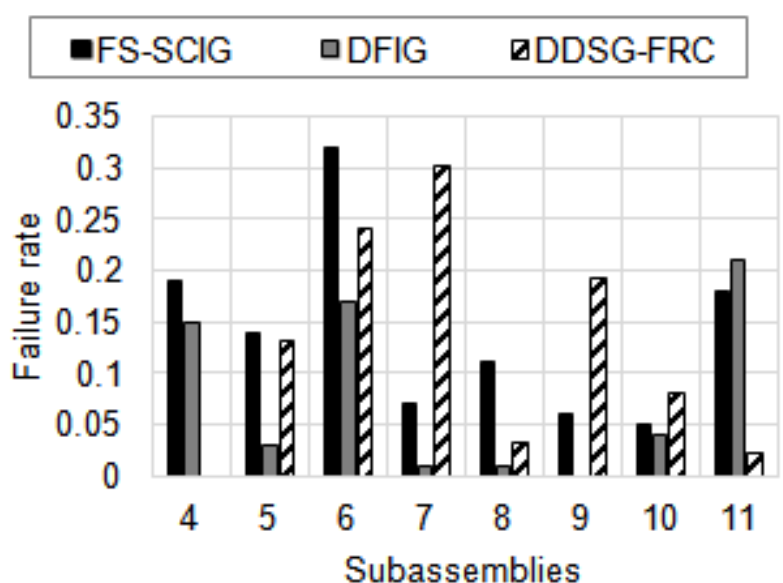

(c)

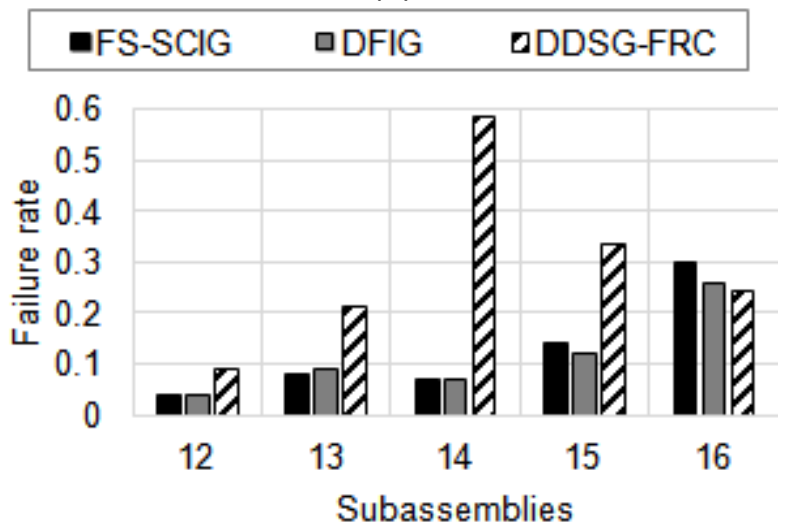

(e)

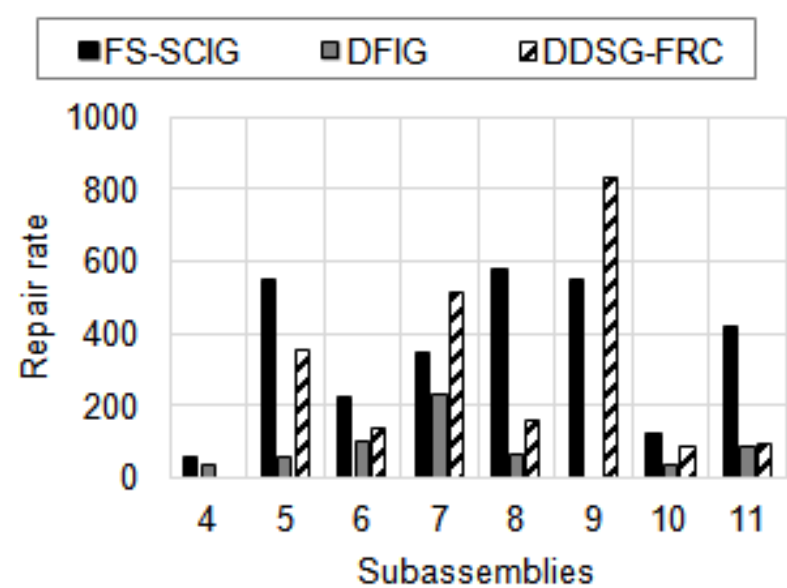

(d)

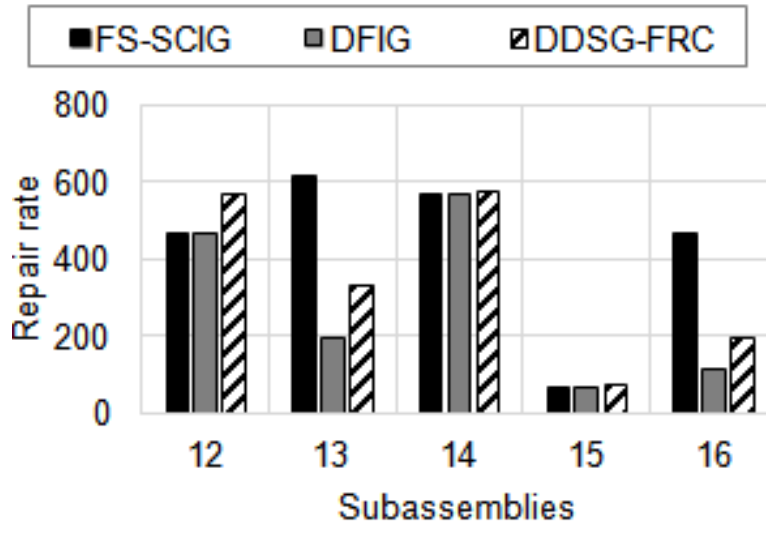

(f)

Fig. 4. Summary of failure rate and repair rate of subassemblies for WTGs. (a) Failure rates of electrical subassemblies, (b) Repair rates of electrical subassemblies, (c)

Failure rates of mechanical subassemblies, (d) Repair rates of mechanical subassemblies, (e) Failure rates of others subassemblies, and (f) Repair rates of others subassemblies. 1: Generator, 2: Converter, 3: Electrical parts (fuses, switches, and cables/connections), 4: Gear box, 5: Yaw system, 6: Blades, 7: Pitch control, 8: Mechanical brake, 9: Air brake, 10: Main shaft, 11: Hydraulic system, 12: Anemometer, 13: Sensors, 14: Hub, 15: Tower, and 16: Other items
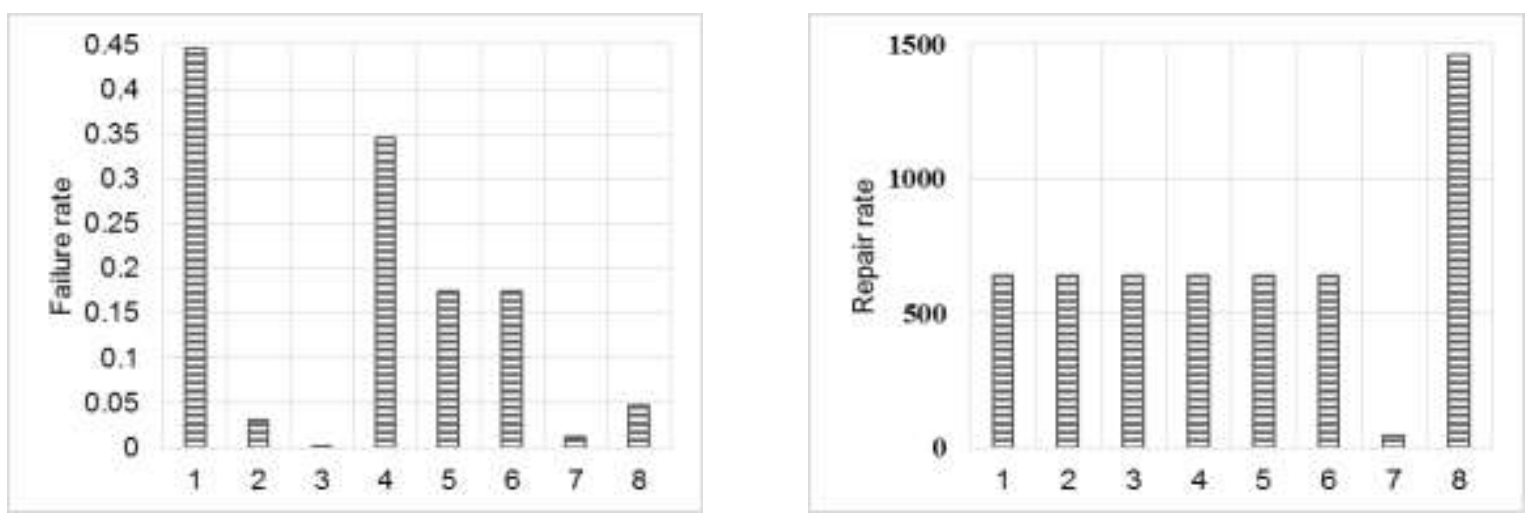
(a)

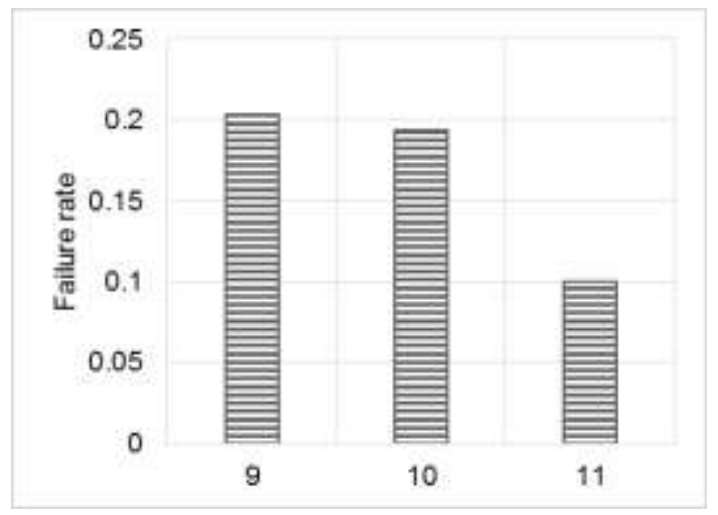

(c)

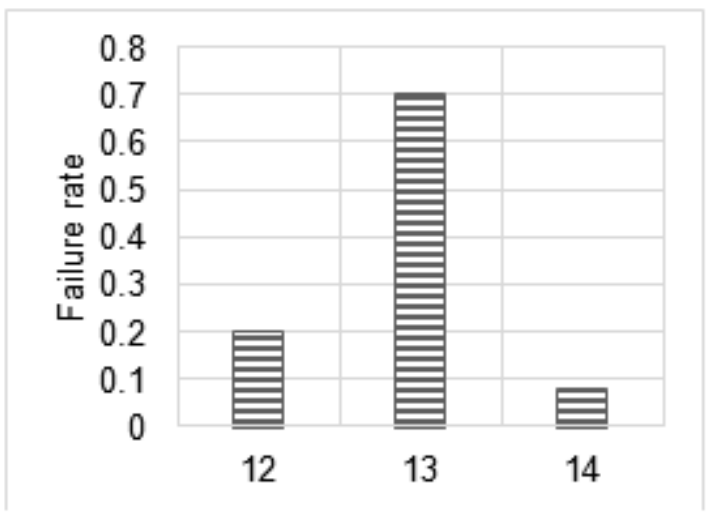

(e) (b)

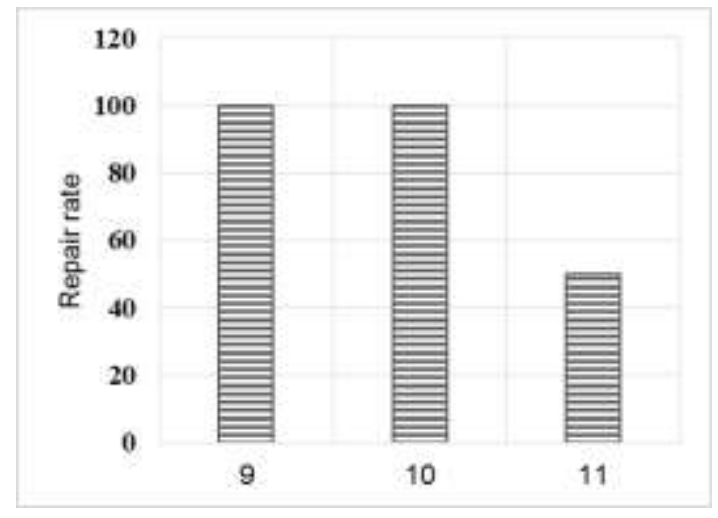

(d)

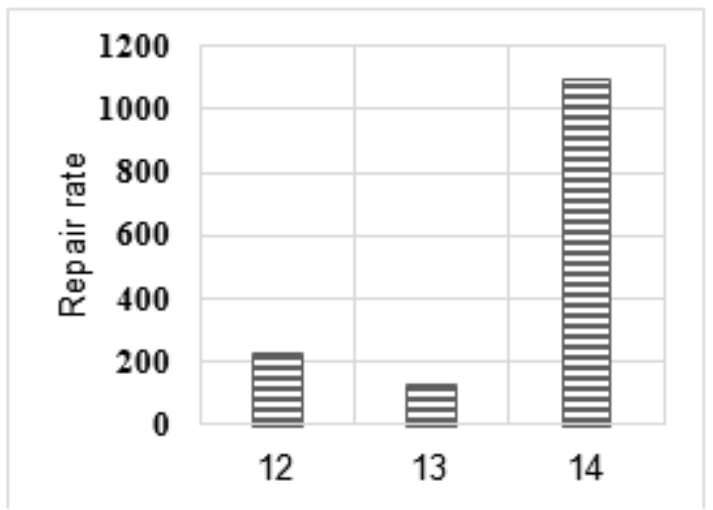

(f)

Fig. 5. Summary of failure rate and repair rate of subassemblies for solar PV systems. (a) Failure rates of BOS subassemblies, (b) Repair rates of BOS subassemblies, (c) Failure rates of storage subassemblies, (d) Repair rates of storage subassemblies, (e) Failure rates of subsystems, and (f) Repair rates of subsystems. 1: Bypass diode, 2: $D C$ switch, 3: AC Switch, 4: AC CB, 5: Differential CB, 6: Grid Protection, 7: connectors (couplers), 8: DC combiner. 9: Charge controller, 10: Battery, 11: Control unit, 12: PV array, 13: DC-AC Inverter, and 14: DC-DC Converter.

\subsubsection{Failure and Repair Rates of Solar-PV Systems}

Fig. 5 shows the failure, and repair rates of solar-PV systems. As shown in Table 1 , the battery storage, and its charge controller is absent in from the grid-connected system with reliable grid, and off-grid systems with deferrable loads. On the other hand, these systems include the DC-DC converter for providing the MPPT function. Unfortunately, the decomposition of all subsystems to their subassemblies in solar-PV systems could not be performed due to the lack of the required failure, and repair data; 
however, the available data are associated with the whole subsystems. These subsystems include the solar-PV array, and inverter. It is depicted from Fig. 5 that:

- The highest failure rate in the BOS subsystem is associated with the bypass diode (Fig 5(a)). This is may be due to the stress factors for the electronic components that increase the failure rate. These factors are temperature stress factor, quality stress factor, environmental stress factor, voltage stress factor, and contact construction stress factor. The AC CB represents the second highest failure rate after bypass diode in BOS subsystem.

$>$ The repair rate of DC combiner is the highest repair rate between all subassemblies of the BOS subsystem, while the repair rate of the connector subassembly is the lowest repair rate among all of the same subsystem as illustrated in Fig 5(b). This means that, the DC combiner has a highest maintainability and the connector has a lowest maintainability. This is due to that the ability of restoring the DC combiner its original state easier than the connectors which need difficult effort to reach the failed connector.

$>$ Although the failure rate of the charge controller represents the highest failure rate of the storage subsystem, it has the highest maintainability as shown in Fig 5(c), and Fig 5(d). This means that this subassembly will have high availability among the all subassemblies in the storage subsystem.

$>$ The AC-DC inverter represents the high failure rate among all solar PV subassemblies. This may due to either the complexity of the AC-DC inverter, or because the AC-DC inverter contains electronic components which significantly affected by various stress factors. Therefore, the lifetime of the ACDC inverter in the solar-PV systems is very low (in the range of 5-10 years) in comparison with the predicted average lifetime of the solar-PV system which is in the range 20-25 years. This means that the inverter will be replaced several times during the lifetime the solar-PV systems.

$>$ Although some literature states that the solar-PV array is the most reliable subassembly of in the solar-PV system, the results show that it comes in the tenth place of the most reliable subassemblies of the solar-PV system. Since huge data of failure, and repair rates are used in estimating median values, and the survey covers many sites of different meteorological conditions, the results in this paper are of a high confidence.

\section{CONCLUSION}

This paper presents a detailed survey of the failure and repair rates of various subassemblies, subsystems, and systems comprising various configurations of WTGs, and solar-PV systems. Various layouts for these systems are also considered in this paper for covering the impacts of different operational modes, and different load types.

The surveyed data and the presented results represent an important step for performing detailed RAM analyses of the presented systems. In addition, they provide the operators with valuable information about setting accurate maintenance schedules for improving the overall reliability of various systems. 
The use of a huge amount of data that covers widespread systems increases the confidence of the presented median values of the failure, and repair rates.

The results show that, the AC-DC inverter has the highest failure rate between all subassemblies of the solar-PV system. The failure rate of the blades represents the highest failure rate of all subassemblies in FS-SCIG. The hub failure rate in direct DDSGFRC configuration shows a significant failure rate among all subassemblies. The failure rate of the hydraulic system in DFIG is the highest failure rate among its subassemblies. The repair rate of the hub, and the air brake are the highest values among the subassemblies of the DFIG, and DDSG-FRC.

\section{REFERENCES}

[1] M. EL-Shimy, ed., "Economics of Variable Renewable Sources for Electric Power Production," Lambert Academic Publishing / Omniscriptum Gmbh \& Company Kg, Germany, ISBN: 978-3-330-08361-5, May, 2017.

[2] M. EL-Shimy, "Chapter 3: Operational Characteristics of Renewable Sources, Challenges, and Future Prospective. In: Economics of Variable Renewable Sources for Electric Power Production," Lambert Academic Publishing / Omniscriptum Gmbh \& Company Kg, Germany, ISBN: 978-3-330-08361-5; May 2017.

[3] Renewables 2017: global status report. REN21, the Renewable Energy Policy Network for the 21st Century. 2017. (http:// http://www.ren21.net/gsr-2017/ )

[4] J. Cochran, L. Bird, J. Heeter, and D. A. Arent, Integrating Variable Renewable Energy in Electric Power Markets: Best Practices From International Experience, Summary For Policymakers, Golden, CO, USA: National Renewable Energy Laboratory, 2012.

[5] National Renewable Energy Laboratory, "Renewable Electricity Futures Study." M. M. Hand, S. Baldwin, E. DeMeo, J. M. Reilly, T. Mai, D. Arent, G. Porro, M. Meshek, and D. Sandor, Eds., 4 vols. Golden, CO, USA: National Renewable Energy Laboratory, 2012, NREL/TP-6A20-52409 [Online]. Available: http://www.nrel.gov/analysis/refutures/.

[6] M. EL-Shimy, "Dynamic Security of Interconnected Electric Power Systems Volume 1" Lambert Academic Publishing / Omniscriptum Gmbh \& Company Kg, Germany, ISBN: 978-3-659-71372-9, May. 2015.

[7] M. EL-Shimy, "Dynamic Security of Interconnected Electric Power Systems Volume 2: Dynamics and stability of conventional and renewable energy systems," Lambert Academic Publishing / Omniscriptum Gmbh \& Company Kg, Germany, ISBN: 978-3-659-80714-5, Nov. 2015.

[8] M. El-Shimy, "Stability-based minimization of load shedding in weakly interconnected systems for real-time applications," International Journal of Electrical Power \& Energy Systems, vol. 70, pp. 99-107, 2015.

[9] J. Hernández, F. Ruiz-Rodriguez, and F. Jurado, "Technical impact of photovoltaic-distributed generation on radial distribution systems: Stochastic simulations for a feeder in Spain," International Journal of Electrical Power \& Energy Systems, vol. 50, pp. 25-32, 2013. 
[10] M. EL-Shimy, "Wind Energy Conversion Systems: Reliability Perspective," in Encyclopedia of Energy Engineering and Technology, 2nd ed., vol. 4, pp.21842206, Taylor \& Francis, New York, 2015.

[11] M. Abdelfatah, M. El-Shimy, and H. Ismail, "Reliability analysis of $220 \mathrm{kV}$ power transformers in Egypt," Ain Shams Engineering Journal, vol. 2, no. 3-4, pp. 183-194, 2011.

[12] V. Smet, F. Forest, J.-J. Huselstein, F. Richardeau, Z. Khatir, S. Lefebvre, and M. Berkani, "Ageing and Failure Modes of IGBT Modules in High-Temperature Power Cycling," IEEE Transactions on Industrial Electronics, vol. 58, no. 10, pp. 4931-4941, 2011.

[13] J. Liu, and N. Henze, "Reliability consideration of low-power grid-tied inverter for photovoltaic application," 24th European photovoltaic solar energy conference and exhibition, Hamburg/Germany, 2009.

[14] G. Petrone, G. Spagnuolo, R. Teodorescu, M. Veerachary, and M. Vitelli, "Reliability Issues in Photovoltaic Power Processing Systems," IEEE Transactions on Industrial Electronics, vol. 55, no. 7, pp. 2569-2580, 2008.

[15] R. Alonso, E. Roman, A. Sanz, V. E. M. Santos, and P. Ibanez, "Analysis of Inverter-Voltage Influence on Distributed MPPT Architecture Performance," IEEE Transactions on Industrial Electronics, vol. 59, no. 10, pp. 3900-3907, 2012.

[16] A. Ahadi, N. Ghadimi, and D. Mirabbasi, "Reliability assessment for components of large scale photovoltaic systems," Journal of Power Sources, vol. 264, pp. 211-219, 2014.

[17] G. Zini, C. Mangeant, and J. Merten, "Reliability of large-scale grid-connected photovoltaic systems," Renewable Energy, vol. 36, no. 9, pp. 2334-2340, 2011.

[18] M. Perdue and R. Gottschalg, "Energy yields of small grid connected photovoltaic system: effects of component reliability and maintenance," IET Renewable Power Generation, vol. 9, no. 5, pp. 432-437, Jan. 2015.

[19] M. El-Shimy, "Probable power production in optimally matched wind turbine generators," Sustainable Energy Technologies and Assessments, vol. 2, pp. 5566, 2013.

[20] A. Ahadi, H. Hayati, and S. M. M. Aval, "Reliability evaluation of future photovoltaic systems with smart operation strategy," Frontiers in Energy, vol. 10, no. 2, pp. 125-135, May 2016.

[21] "The Wind Energy Operations \& Maintenance Report," windenergyupdate.com. [Online]. Available: http://www.windenergyupdate.com/. [Accessed: 22-Dec-2017].

[22] W. Qiao and D. Lu, "A Survey on Wind Turbine Condition Monitoring and Fault Diagnosis-Part I: Components and Subsystems," IEEE Transactions on Industrial Electronics, vol. 62, no. 10, pp. 6536-6545, 2015.

[23] E. Echavarria, B. Hahn, G. J. W. V. Bussel, and T. Tomiyama, "Reliability of Wind Turbine Technology Through Time," Journal of Solar Energy Engineering, vol. 130, no. 3, p. 031005, 2008. 
[24] N. Gupta, R. Garg, and P. Kumar, "Sensitivity and reliability models of a PV system connected to grid," Renewable and Sustainable Energy Reviews, vol. 69, pp. 188-196, 2017.

[25] D. P. Kaundinya, P. Balachandra, and N. Ravindranath, "Grid-connected versus stand-alone energy systems for decentralized power-A review of literature," Renewable and Sustainable Energy Reviews, vol. 13, no. 8, pp. 2041-2050, 2009.

[26] D. Siyambalapitiya, S. Rajapakse, S. D. Mel, S. Fernando, and B. Perera, "Evaluation of grid connected rural electrification projects in developing countries," IEEE Power Engineering Review, vol. 11, no. 2, pp. 70-74, 1991.

[27] M. Sidrach-De-Cardona and L. López, "Evaluation of a grid-connected photovoltaic system in southern Spain," Renewable Energy, vol. 15, no. 1-4, pp. 527-530, 1998.

[28] U. Atikol, "Impact of cogeneration on integrated resource planning of Turkey," Energy, vol. 28, no. 12, pp. 1259-1277, 2003.

[29] A. Fernández-Infantes, J. Contreras, and J. L. Bernal-Agustín, "Design of grid connected PV systems considering electrical, economical and environmental aspects: A practical case," Renewable Energy, vol. 31, no. 13, pp. 2042-2062, 2006.

[30] "The Wind Energy Operations \& Maintenance Report," windenergyupdate.com. [Online]. Available:

http://www.windenergyupdate.com/. [Accessed: Jul-2017]. 